\title{
Pequenas-grandes representações do Império Português: a série postal "Modalidades Desportivas"(1962)
}

\author{
Small-large representations of the Portuguese Empire: \\ the stamp series "Sporting Modalities" (1962)
}

Victor Andrade de Melo

\section{Introdução}

No pós-Segunda Grande Guerra, um vento de liberdade varreu os continentes asiático e africano. Impulsionados pelo novo quadro geopolítico, gestaram-se movimentos sociais que, fazendo uso de diferentes estratégias e tendo em conta as fronteiras estabelecidas pelos países colonizadores, reivindicavam o rompimento dos laços coloniais.

\footnotetext{
Victor Andrade de Melo é professor do Programa de Pós-Graduação em História Comparada do Instituto de História da Universidade Federal do Rio de Janeiro (victor.a.melo@uol.com.br).

Este estudo foi realizado com financiamento da Fundação de Amparo à Pesquisa do Estado do Rio de Janeiro/ Faperj (auxílio Jovem Cientista de Nosso Estado) e do Conselho Nacional de Desenvolvimento Científico e Tecnológico/CNPq (Bolsa Produtividade em Pesquisa/1-D). O autor agradece, pelas contribuições à pesquisa que originou o artigo, a Rafaela Balsinhas e Marcelo Bittencourt

Artigo recebido em 14 de maio e aprovado para publicação em 28 de agosto de 2012.
} 
As nações colonizadoras, frente a essa realidade, de distintas formas e com peculiaridades em cada localidade, foram compelidas a encaminhar processos de descolonização (Ferro, 1996). Portugal foi um dos países que mais relutaram em encerrar seus laços coloniais. Havia ao redor de tal postura motivações de ordem cultural - a relevância da representação de império na construção da ideia de nação portuguesa; de ordem econômica - a importância dos territórios ultramarinos para as finanças nacionais; e de ordem política - a relação do projeto do Estado Novo com o colonialismo (Pimenta, 2010).

Tal atitude desencadeou, sobre o governo português, pressões das mais diversas, inclusive de entidades internacionais que se fortaleceram no pós-guerra. ${ }^{1}$ Perante esse quadro, os dirigentes do país reagiram de formas múltiplas. Uma das estratégias adotadas foi a promoção de mudanças na legislação nacional. Revogou-se, por exemplo, em 1951, o Ato Colonial. Entre outras coisas, a partir de então, as colônias passaram a ser denominadas "províncias ultramarinas", um suposto sinal de maior integração do Império. ${ }^{2}$

Concretamente, no que tange ao colonialismo português, "a conjuntura externa não consegue provocar alterações de fundo, nomeadamente ao nível da política indígena" (Castelo, 1998: 51). Nos anos 1960, os limites das mudanças propostas pela metrópole foram expostos pela ação de países africanos recém-independentes que passaram a integrar os organismos internacionais, ${ }^{3}$ pelos movimentos anticoloniais que eclodiram nos territórios portugueses em Africa (inclusive pela via armada, a partir de 1961, em Angola) e mesmo pelas reivindicações de colonos por maior autonomia e respeito às peculiaridades de cada província.

O governo português, em resposta, tanto fez uso do poder bélico para combater os movimentos independentistas quanto incrementou ações no sentido de promover uma maior integração das províncias, sempre de forma ambígua, pois também cresceram as iniciativas de controle, notadamente com uma intensa atuação da Polícia Internacional e de Defesa do Estado (Pide).

Nesse contexto, em abril de 1961, Adriano Moreira é nomeado ministro do Ultramar. Esse advogado, político, cientista social e professor de muitas instituições acadêmicas, inclusive da Escola Superior Colonial, para a qual contribuiu com a reformulação dos programas e da perspectiva de atuação, demonstrava a intenção de conjugar "o respeito pelos usos e costumes locais com o propósito de assimilação", a fim de garantir a suposta "sociedade multirracial que se contém nos limites do território português" (Castelo, 1998: 62). ${ }^{4}$

A administração metropolitana passou a, mais enfaticamente, defender a "peculiaridade da colonização portuguesa", supostamente responsável pela construção de sociedades harmônicas, mobilizando para tanto as ideias lusotropicalistas de Gilberto Freyre. Segundo Castelo, essa referência 
"inventada" com base em pressupostos históricos e numa imagem essencialista da personalidade do povo português, além de ter servido a interesses político-ideológicos conjunturais durante o Estado Novo, ajudou a perpetuar uma imagem mítica da identidade cultural portuguesa, concedendo-lhe autoridade "científica" de que até aí não dispunha (1998: 14).

Foi nesse cenário que, em 1962, o governo português lançou a série postal "Modalidades Desportivas": 48 selos, seis para cada colônia (Angola, Cabo Verde, Estado da Índia, Guiné Portuguesa, Macau, Moçambique, São Tomé e Príncipe, Timor), com distintos esportes representados. Este estudo irá analisar a emissão desse conjunto de estampilhas, em especial de dois selos dedicados a Cabo Verde, com o intuito de discutir a presença da prática esportiva no âmbito da política colonial portuguesa da década de 1960.

Tais estampilhas foram por dois motivos escolhidas para análise: a) embora tenha sido comum a presença do esporte em séries postais portuguesas da década de 1960, "Modalidades Desportivas" é a única em que o tema está diretamente relacionado às colônias; b) os selos foram lançados em um momento peculiar do colonialismo português, marcado por tensões e conflitos que levariam a seu fim nos anos 1970.

Nossa hipótese é que, por meio dos selos, a prática esportiva foi mobilizada como estratégia para conformar uma representação do "modo português de estar no mundo", para construir uma autoimagem de "predisposição para a comunicação, para a partilha, para a comunhão", que remetia a uma "ideia de igualdade social, esvaziando de conteúdo a crítica ao colonialismo português" (Castelo, 1998: 109).

Uma das características mais marcantes dos selos é o fato de que por trás de sua aparente "modéstia" se encontra um grande aparato: trata-se de uma produção do Estado, não poucas vezes difundindo representações interessantes para certo projeto político (Salcedo e Gomes, 2009). Circulando de forma ampla no cotidiano, as mensagens que portam as estampilhas têm algo de educativo, sendo um artifício de propaganda. Por tal perfil, estamos de acordo que "o seu conteúdo simbólico representa informação de potencial relevância ao desenvolvimento de narrativas históricas" (Salcedo e Santana, 2010: 46).

Osmond chama a atenção para o fato de que os selos são o "produto final de um normalmente demorado e por vezes tenso processo de criação, planejamento e execução. Entender esse processo pode prover o historiador com informação valiosa sobre o significado cultural e ideológico do objeto" (2008: 316).

É possível considerar os selos como artefatos que integram a cultura visual de um tempo. Nesse sentido, vale ter em conta o diálogo que Knauss (2006: 
114) estabelece com W. J. T. Mitchell, sugerindo que o estudo da imagem deve ser encarado como "um jogo complexo en tre visualidade, aparatos, instituições, discursos, corpos, e figuração".

Vale ainda considerar que, no âmbito da história do esporte, como identificam Osmond e Philips (2011), não tem sido comum o uso de selos como fontes. ${ }^{5}$ Para os autores, trata-se de um desperdício não ter em conta as estampilhas, já que são muitas as suas possíveis contribuições para que sejam lançados novos olhares sobre o fenômeno esportivo, inclusive para prospectar como a prática foi mobilizada em certas estratégias governamentais, não poucas vezes relacionada a representações identitárias. É esse esforço que se pretende entabular neste artigo.

\section{Selos e esportes na politica colonial portuguesa dos anos 1960}

Na década de 1960, ainda que tenham sido cosméticas as mudanças na relação entre a metrópole e as colônias, algumas ações foram efetivamente encaminhadas no intuito de consolidar representações que reiterassem a adesão de Portugal às ideias lusotropicalistas de Freyre. Já que, ao menos nos discursos, referendados pela legislação e pela "ciência", tratava-se de uma nação harmonicamente formada por territórios na Europa, na Ásia e na África, era necessário de alguma forma consolidar essa imagem.

Para tanto, entre outras estratégias o governo português fez uso, segundo Rafaela Balsinhas (2011: 11), "da pintura, da escultura, do cinema, da arquitetura e também das artes gráficas, por meio das imagens dos selos postais". De acordo com a autora, "o Estado Novo investia na produção das emissões postais, criando efemérides e representações próprias para cada colônia, difundindo, com isso, um significativo número de imagens sobre o imaginado ultramar". Ou seja, as estampilhas eram veículos das visões da metrópole sobre as províncias, deixando entrever algumas de suas estratégias coloniais.

Sentem-se também desdobramentos do contexto dos anos 1960 no âmbito da prática esportiva. De um lado, em algumas províncias, notadamente em Angola, Moçambique e Guiné, os clubes foram espaços de organização de movimentos de contestação, o que desencadeou o aumento do controle sobre seu funcionamento. De outro lado, sugere-se que o esporte tenha sido mobilizado pelo governo português como uma forma simbólica de celebrar os laços entre as diversas partes constituintes do Império (Melo e Bittencourt, 2012).

Devemos ter em conta que o esporte, que desde o século XIX vinha se afirmando como indicador de progresso e civilidade, no pós-Segunda Grande Guerra, por motivos diversos (entre os quais a Guerra Fria e o aumento da in- 
fluência dos meios de comunicação), se tornou ainda mais relevante no cenário mundial, ocupando as entidades e competições esportivas um rol protagonista em um mundo crescentemente transnacionalizado. Nesse contexto, a prática se fortaleceu como ferramenta de construção de identidades nacionais (Hobsbawm, 2007).

A vinculação ao esporte, com seus discursos de fraternidade universal, se constituiu portanto para o governo português em uma estratégia narrativa de alcance internacional: demonstrar que a nação estava sintonizada com o planeta. Além disso, por meio da prática celebrava-se o sentimento de lusitanismo que a todos deveria unir em torno de um mesmo fim: a glória do Império. Exaltava-se a "raça portuguesa", fruto da multirracialidade, capaz de se superar nos grandes "combates internacionais" (emulados pelas competições), mesmo que oriunda de um país pequeno, que tinha encontrado muitas dificuldades em sua história, somente superadas graças ao valor de seu povo.

É interessante observar que outros países colonizadores já vinham mobilizando o esporte no sentido de consolidar laços coloniais ou pós-coloniais (com intuitos até mesmo neocoloniais). Podemos citar a experiência dos Commonwealth Games, que começaram a ser realizados em 1930 com o nome de Jogos do Império Britânico, e seguem sendo até hoje disputados pelos países que compõe a comunidade.

Aliás, é no mesmo número do Boletim Geral do Ultramar (1961: 216) no qual se faz um minucioso relato dos problemas desencadeados pelos movimentos de contestação em Angola, com o início dos conflitos armados independentistas em 1961, que é lançado o comunicado sobre a constituição de uma comissão para a organização dos "Jogos Desportivos do Mundo Português".

A mobilização do esporte se fortalecia com o fato de que equipes portuguesas viviam um bom momento no cenário internacional de competições. Os anos 1960 ficaram conhecidos como a "década de ouro" do mais popular clube de futebol do país: o Sport Lisboa e Benfica, que se sagrou vitorioso em importantes campeonatos. A seleção de Portugal, na esteira desse sucesso, obteve seu melhor resultado até então e durante muitos anos: o terceiro lugar na Copa do Mundo de 1966.

O futebol contribuía para a exaltação da ideia de que havia um caminho de ida e volta nos encontros culturais promovidos entre europeus e africanos/asiáticos. Devemos lembrar que uma das razões do sucesso do Benfica e do selecionado nacional foi a atuação de um dos melhores futebolistas de todos os tempos, o moçambicano Eusébio, até hoje cultuado como um dos grandes ídolos de Portugal, na época também celebrado como exemplo positivo das peculiaridades do colonialismo português (Armstrong, 2004). Além disso, destacavam-se 
as atuações do angolano José Águas e do moçambicano Mário Coluna. ${ }^{6}$ Assim, como bem identifica Santos (2000),

A equipa do Benfica fornece os elementos simbólicos que ilustram o ideal de população: jovens do continente e jovens das já então chamadas Províncias Ultramarinas a colaborar em equipa, disciplinados na conquista de um objetivo comum. [s]imboliza o colonialismo ideal, um grupo unido e coerente na sua acção a lutar em torno de objectivos comuns e igualmente partilhados por todos. A alegoria à nação é muito fácil de se realizar, ambas comunidades multirraciais e multicontinentais: tanto a equipa como a nação são tidas como um corpo, uma entidade única, espaço de consenso de ideais.

Sugere a autora que, se os jogadores negros africanos eram considerados exemplos da garra e da fibra lusitana, isso se dava porque, supostamente, Portugal lhes oferecera a oportunidade de desenvolver tais comportamentos. Dessa forma, se eram citados como exemplos da pluralidade do colonialismo português, também reposicionavam as hierarquias no cenário colonial.

Enfim, não surpreende que, àquela altura, pelos aspectos elencados, o governo Salazar integrasse o esporte, notadamente o futebol, em suas estratégias de propaganda política, no que posteriormente ficou conhecido como "trilogia dos f's": futebol, Fátima e fado (Coelho e Pinheiros, 2002; Serrado, 2009).

\section{A série postal "Modalidades Desportivas"}

Se desde o século XIX os selos emitidos pela metrópole circulavam pelos territórios portugueses na África e na Ásia, foi somente a partir de 1931 que passou a haver emissão postal exclusiva para as colônias. De acordo com Balsinhas (2011), até 1949 a temática dessas estampilhas comumente ressaltava a longa presença de Portugal nos continentes.

No quadro de reformulação das relações com as províncias, elementos locais começaram a se tornar mais comuns nos selos, inclusive as representações dos naturais: "O desenho postal procurava demonstrar, portanto, que os vários grupos sociais não abandonaram completamente a sua cultura: ao invés de subjugar culturalmente os nativos, o português permitia que esses cultivassem certas crenças e tradições" (Balsinhas, 2011: 95). A série "Modalidades Desportivas" parece se ajustar parcialmente a tais parâmetros.

É significativo o montante de selos da série emitidos: 21 milhões (Portugal, 1961). ${ }^{7}$ Comparemos com outras emissões postais do mesmo ano. Dedicadas 
à erradicação do paludismo, também circulando nas oito províncias, foram lançados 2,2 milhões de estampilhas (Portugal, 1962a). Não chega a surpreender, e deve ser ressaltado, que o governo português tenha preferido lançar mais selos com um tema com o qual se estabelece uma relação imediata positiva (o esporte) do que com outro que levanta um problema de saúde, ainda que também expresse a determinação de buscar a solução. De toda maneira, é relevante observar que a diferença tenha sido da ordem de quase 10 vezes.

A emissão total das três estampilhas que homenageavam o $50^{\circ}$ aniversário da Guarda Nacional Republicana foi de 10 milhões (Portugal, 1962b). Vale destacar que mesmo uma instituição tão importante para o regime tenha merecido em sua homenagem um menor número de selos do que os lançados com os temas esportivos, embora se entenda que tenha sido um conjunto mais destinado a circular no continente europeu. De qualquer forma, trata-se de mais um indicador da grandeza da série "Modalidades Desportivas". É possível supor que houve uma clara intenção de fazê-la circular muito pelos vastos territórios portugueses.

Os 48 selos da série guardam entre si muitas semelhanças. ${ }^{8}$ Têm o mesmo tamanho (denteado $131 \frac{1}{2}, 30 \mathrm{~mm} \times 30 \mathrm{~mm}$ ), são confeccionados com papel esmalte (superfície acetinada e brilhante), os temas estão estampados na diagonal, aproximadamente no centro. Todos têm escrito "República Portuguesa" no vértice superior e o nome da província no vértice inferior. Os valores variam de 10 centavos, o mais barato (do Estado da Índia), ${ }^{9}$ a 20 escudos, o mais caro (de São Tomé e Príncipe); os de Macau estão expressos em patacas.

Desde 1911 havia iniciativas para tentar garantir ao redor do escudo a unidade monetária nas colônias, um processo conduzido pelo Banco Nacional Ultramarino, que desde 1864 atuava suprindo a circulação de moedas nos territórios da África e Ásia. Todavia, havia muitas peculiaridades. Macau usava a pataca, que também circulou em Timor até 1959. Angola contava com uma moeda (angolar) e um banco (Banco de Angola) próprios. Além disso, havia diferenças cambiais. Mesmo assim, contando que os valores foram estabelecidos pela metrópole, podemos fazer uma comparação dos selos de "Modalidades Desportivas" com outras emissões do mesmo ano.

A série " $50^{\circ}$ aniversário da Guarda Nacional Republicana" tem estampilhas com os seguintes preços: $1 \$ 00,2 \$ 00$ e $2 \$ 50$. Já os quatro selos da série "X Congresso Internacional de Pediatria" trazem estampados $\$ 50,1 \$ 00,2 \$ 80$ e $3 \$ 50$. As estampilhas "Europa", que possuíam similares em outros 18 países do continente, mantinham-se entre $1 \$ 00$ e $3 \$ 50$.

É possível inferir que o alto valor dos selos mais caros da série "Modalidades Desportivas" (além do já citado de São Tomé e Príncipe, há o de $12 \$ 50$ de Cabo Verde, e os de 15\$00 de Angola, Estado da Índia, Guiné Portuguesa, Mo- 
çambique e Timor) tenha relação com o custo da troca de cartas entre a metrópole e as colônias (bem como entre estas). Já os de valores mais baixos poderiam ser usados para correspondências internas.

Essa apreensão se reforça quando consideramos que a série "Homem de 3 raças", exclusiva de Angola, tinha selos de $\$ 50,1 \$ 00$ e $2 \$ 00$. Da mesma forma, "Erradicação do Paludismo", que como vimos circulou nos territórios ultramarinos, valia $2 \$ 50$. Enfim, argumentamos que o grande espectro de valores da emissão "Modalidades Desportivas" é mais um indício de que as estampilhas foram produzidas para circular em distintos estratos sociais e localidades, sem perder de vista o que sugere Balsinhas (2009):

A emissão de séries postais para as colônias em separado das emitidas em Portugal me faz crer que estas eram produzidas, sobretudo, visando contemplar aqueles que habitavam as áreas coloniais, que se correspondiam com suas famílias e amigos que muitas vezes ficaram no velho continente ou mesmo que migraram para outras colônias que não a sua, sem mencionar o caso dos assimilados.

Os selos foram impressos em duas tradicionais gráficas portuguesas: a Litografia Nacional e a Litografia Maia, ambas localizadas na cidade do Porto. Dois artistas ficaram responsáveis pela composição: José de Moura (estampilhas de Cabo Verde, Guiné Portuguesa, Angola, São Tomé e Príncipe) e Rui Preto Pacheco (Moçambique, Macau, Timor, Estado da Índia), ambos com experiências pregressas na produção de séries postais.

Segundo Teresa Matos Pereira, José de Moura foi um dos artistas que erigiram um imaginário sobre as colônias africanas:

uma economia visual que foi construindo e reconfigurando a imagem dos territórios africanos (...), das pessoas e das culturas ou da história das relações que envolvem Portugal e África (...) atendendo aos desejos de domínio, de libertação e de pertença, que se projectam no suporte artístico e/ou documental (2010: 3).

Já Rui Preto Pacheco é mais conhecido para além de sua atuação nas províncias. Foi integrante do "Grupo de Artistas Portugueses", coletivo constituído em 1945 com o intuito de defender o que os envolvidos consideravam valores típicos da arte de Portugal. Depois de uma notável trajetória como retratista em Lisboa, por problemas profissionais deslocou-se para Angola, onde se estabele- 
ceu por cerca de uma década e contribuiu para a construção de representações sobre a África.

Podemos perceber que foram convidados artistas que tanto tinham demonstrado habilidade na confecção de selos quanto possuíam algum conhecimento ou relação com o continente africano, o que indica certo grau de compromisso do governo metropolitano com a produção da série.

Os esportes representados não são somente os que seguem os padrões usuais do campo esportivo (como atletismo, futebol, vôlei), mas são também certos entretenimentos (caça, pesca, mergulho, por exemplo) e outras atividades físicas (como a ginástica e as lutas representadas nos selos da Guiné Portuguesa e de Macau). ${ }^{10}$

Como tais esportes teriam sido escolhidos e distribuídos pelos selos/colônias? A portaria que determinou a emissão apenas informava que as estampilhas deveriam ter como motivos "diversas modalidades de desporto praticadas nas províncias" (Portugal, 1961), e estabelecia também as cores a serem utilizadas. A notícia publicada na seção de filatelia do Boletim Geral do Ultramar (1962: 204) tampouco dá maiores detalhes.

Podemos supor que os artistas tiveram algum grau de liberdade para criar, ${ }^{11}$ fazendo uso de sua experiência anterior, podendo ou não ter dialogado, em distintos graus, com as instâncias governamentais. De toda forma, é possível perceber que nas escolhas há algo de diálogo com o local, algo de aleatório e um certo princípio geral.

Assim, por exemplo, não surpreende que nos selos de Macau tenham sido representados o tênis de mesa e o badminton, fortes naquela província em função da proximidade com a China, mas é curioso que não tenha aparecido, no que se refere a essa localidade, o também apreciado basquete, cuja presença entre as estampilhas de Moçambique pode ser considerada ajustada ao que de fato ocorria nessa colônia. Nesse caso, contudo, é de estranhar não aparecer o futebol, como o é no caso de Angola. O velho esporte bretão integra a série de Timor, uma escolha bastante controversa, como o é no caso da presença do automobilismo entre as estampilhas da Guiné Portuguesa (tal modalidade estaria melhor representada entre os selos angolanos). ${ }^{12}$

Para além de ser ou não resultado de desconhecimento por parte dos artistas, percebe-se sim nessas escolhas uma postura ambígua: reconhece-se algo da peculiaridade de cada colônia, mas se constrói uma representação mais ampla, a de que o esporte está espalhado por todo o Império, como signo de progresso e de união do povo português (que, afinal, nas estratégias discursivas, é um só).

Isso fica claro quando percebemos que há certa regularidade na distribuição por província: práticas que remetem ao local (por fazerem referência à "exuberante" natureza, por conectarem-se com algum aspecto "nativo" ou por 
realmente serem usuais no território), modalidades tradicionais do campo esportivo (coletivas ou individuais, valorizadas internacionalmente, que expressariam as supostas contribuições da metrópole para a civilização da colônia), esportes ligados à tecnologia (o que exaltaria a ideia de progresso, outra suposta contribuição do colonizador).

A conjugação desses elementos compõe o quadro representacional de cada província. No caso de São Tomé e Príncipe, por exemplo, há um maior número de referências à exuberante natureza, mas o atletismo, a ginástica artística e o handebol lembram a presença civilizacional dos portugueses (que também se manifesta nos outros selos, já que o meio ambiente está sendo produtivamente usado, não é mais bárbaro ou agressivo aos seres humanos). Esse confronto de imagens é também explícito no caso das estampilhas da Guiné Portuguesa (o automobilismo e o tênis versus o tiro/caça e a luta nativa) e de Timor (caça versus ginástica e futebol).

O que mais se destaca, de fato, é que todos os personagens retratados são mestiços/naturais, como se pode perceber notadamente pelo tom da pele, entre outras características corporais, variáveis inclusive entre os representados, intra e extra província. Trata-se claramente de uma tentativa de expressar e exaltar a "multiplicidade racial" que compunha o Império.

Um detalhe importante é que os personagens são exibidos em posturas ativas e altivas, como protagonistas, não como coadjuvantes ou secundários. Somente nos selos de Moçambique mulheres são representadas, o que pode denotar o reforço da ligação do esporte com as ideias de virilidade e masculinidade, relacionadas à imagem de uma raça forte e próspera. Esse aspecto chamou a atenção de Balsinhas, que percebe inclusive as diferenças em relação às representações comuns em selos anteriores:

a força e a virilidade, particularmente dos negros e dos mestiços, parecia, agora, estar menos associada à violência e à criminalidade, como a antropologia física - com base na frenologia e na antropometria - sustentava nas décadas anteriores. O vigor físico era, agora, apreciado e as características corporais dos mestiços e negros, anteriormente vistas com desconfiança, passavam a ser celebradas pelo regime através desta emissão postal (2011: 102).

Atentemos, contudo, para uma peculiaridade. Para celebrar uma importante conquista futebolística, foram lançados em 1963 os selos "Dupla Vitória do Sport Lisboa e Benfica na Taça dos Clubes Campeões” (Portugal, 1963). A tiragem foi significativa -6 milhões de $1 \$ 00$ e 1,5 milhão de $4 \$ 30$. Há uma diferença 
considerável dessas estampilhas em relação à da série "Modalidades Desportivas".

Uma das marcas principais da prática esportiva, no que se refere à sua performance pública e construção de representações, é o forjar e celebrar de heróis e atos heróicos. Ao contrário dos selos que comemoravam a vitória do Benfica, os das colônias não exibiam explicitamente um nome ou conquista em especial; uma noção generalizada de nativo era o motivo central. Marcava-se, assim, a distinção da metrópole em seu envolvimento com o esporte.

Melo (2010), considerando a adesão ao esporte como um dos indicadores de vinculação a projetos de modernidade, argumenta que a tardia organização do campo esportivo em Portugal é uma das expressões da sua relação peculiar com o ideário e imaginário modernos. Em outro estudo (2011b), esse autor destaca que, nesse sentido, não surpreende que em algumas colônias, por particularidades históricas diversas, como é o caso de Cabo Verde, a prática se tenha estruturado pari passu com a metrópole.

A despeito disso, a ideia geral expressa na série "Modalidades Desportivas" é que a presença do esporte nas províncias teria sido uma suposta contribuição do português/europeu para a adoção de hábitos superiores por mestiços/negros que traziam em si muito do glorioso passado do colonizador.

A representação construída é a de que Portugal era o mensageiro do progresso, da civilização, do desenvolvimento. Mais ainda, sua intervenção teria supostamente respeitado as peculiaridades locais, promovendo encontros culturais que teriam forjado um ente superior que caminharia para dar fim ao atraso do chamado indígena.

\section{Dois selos de Cabo Verde: reforçando peculiaridades de uma província}

O caso de Cabo Verde merece uma discussão mais aprofundada tanto pela relevância da presença do esporte na história da província quanto pelo espaço que o arquipélago ocupa na memória colonial:

primeiramente como espaço do império que validava o mítico desígnio português de propagação da civilização, tendo em conta a celebração propagandística sobre o nível civilizacional da sua população; segundo, como espaço construído a partir da intervenção colonial portuguesa, uma vez que as ilhas eram desabitadas quando da chegada dos navegadores e da instalação dos primeiros colonos, o que corroborava o seu mito de origem a partir do tempo histórico português: é como se Portugal fosse a verdadeira medida histórica de um tempo zero a partir 
do qual se devia começar a contar a antropodisseia das ilhas cabo-verdianas (Barros, 2010: 2).

Nessa colônia, em virtude de uma série de ocorrências históricas, conforma-se uma elite crioula já no século XVIII. Na transição dos séculos XIX e $\mathrm{XX}$, uma intelectualidade local ganha força como mediadora entre a metrópole e a população, entabulando, inclusive, a construção de representações sobre "o jeito de ser cabo-verdiano" que embasavam estratégias de resistência às ingerências metropolitanas.

Não se tratava de um processo de busca de independência. Pelo contrário, os cabo-verdianos, lidando com o fato de que Portugal sobrepunha as noções de império e nação, declaravam sua lealdade à metrópole e reivindicavam, por tal atitude, o pleno reconhecimento de Cabo Verde como parte do país. Tratava-se de "uma luta não propriamente contra a soberania nacional, mas contra o trato colonial. Ou seja, aceitam os pressupostos nacionalizantes, mas propugnam a eliminação dos marcos diferenciais legitimadores das práticas coloniais" (Fernandes, 2006: 42).

À gestação de discursos identitários correspondiam iniciativas de “materializá-los" por meio de elementos diversos. Melo argumenta que aí se encontra uma das possíveis explicações para o precoce desenvolvimento do campo esportivo no arquipélago:

a rápida adesão ao esporte parece ter algum grau de relação com o conjunto de iniciativas que visavam subverter a consideração do colonizador de que o natural se tratava de "alguém menor": civilizado que era, em certa medida algo reconhecido pela própria metrópole, que concedia ao arquipélago certas exceções no tratamento colonial, podia exigir uma consideração diferenciada. Demonstrar hábitos modernos, entre os quais fazer esportes e cuidar da saúde e do corpo, para além do óbvio prazer que tais atividades podiam oferecer, reforçava a ideia tão mobilizada, ora mais ora menos explícita e sempre com um fundo rácico, de que Cabo Verde era uma colônia distinta, superior (2011: 34). ${ }^{13}$

Deve-se observar que uma das ideias-chave das representações de "cabo-verdianidade", o valor do mestiço, foi constantemente mobilizada ao redor do esporte, notadamente de duas modalidades, o golfe e o críquete. Nos discursos, o envolvimento precoce e intenso com práticas tão "civilizadas" teria sido possível porque o crioulo cabo-verdiano soubera aproveitar o melhor dos 
dois mundos que o constituíram: nem só africano, nem só europeu, um bocado dos dois, ainda que tenham sido enfáticos os debates sobre o quanto de cada um.

Os selos da emissão "Modalidades Desportivas" dedicados a Cabo Verde referenciam algo dessa trajetória do esporte na colônia. Se as práticas escolhidas seguem aproximadamente o padrão da série, apresentam também algumas importantes peculiaridades que merecem ser destacadas. Ao contrário do que se observa nas estampilhas das outras províncias, não há práticas relacionadas à tecnologia, nem qualquer exaltação de uma natureza exuberante ou uso de imagens de uma África "nativa". Essa opção reforça a ideia de que Cabo Verde já se encontrava em "estágio civilizacional” avançado, não sen do tão necessário explicitar as contribuições do Império, óbvias que já o eram.

São representados um esporte que exaltava a ideia de raça forte (o atletismo, que de fato não era muito desenvolvido na província na ocasião), ${ }^{14}$ outro que era efetivamente apreciado pela população local (o boxe) e as duas modalidades já citadas, muito importantes na história da colônia: o críquete e o golfe. Debruçar-nos-emos mais detidamente sobre os dois selos que representaram estas práticas.

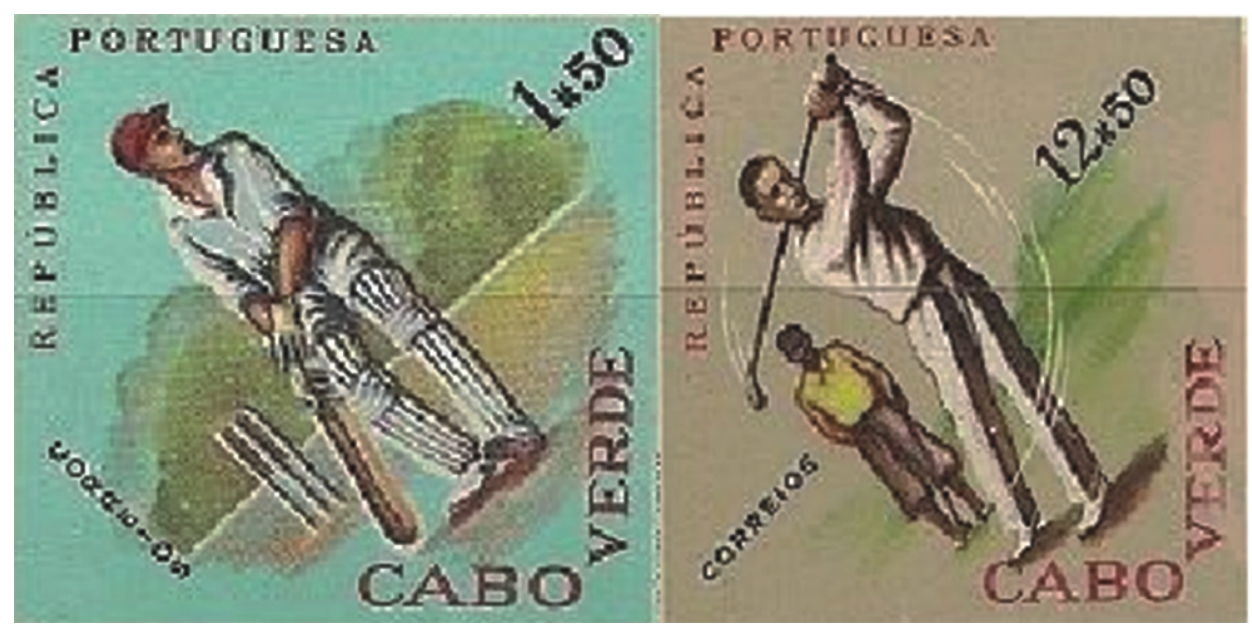

Era habitual, nas diversas localidades em que os ingleses se instalavam, a criação de clubes. Segundo Barros (1981 e 1998), já no século XIX um grupo de britânicos jogava golfe e críquete em São Vicente. Ainda que tais agremiações fossem muito restritas, nos espaços de interface os cabo-verdianos foram tomando conhecimento e começando a praticar os esportes. 


\section{Pequenas-grandes representações do Império Português}

No caso do golfe, uma das peculiaridades é o fato de que se construiu uma representação de que Cabo Verde é o único lugar do planeta onde este é um esporte popular. Vejamos, por exemplo, o posicionamento de Baltasar Lopes, uma das lideranças intelectuais do arquipélago:

Como se sabe, o golfe pertence ao número das atividades desportivas reservadas ao escol social, definido, em regra, pelas suas disponibilidades financeiras. Ora, em São Vicente assiste-se (assistiu-se sempre no que creio poder afirmar) ao fato curioso de a prática do golfe ter sido sempre livre, isto é, aberta a todas as camadas da população, bastando apenas o gosto pela modalidade e o mínimo de aparelhagem técnica (apud Barros, 1981: 5).

Mais ainda, ao redor da modalidade construiu-se uma memória de luta e resistência: contra os ingleses (que dificultavam aos naturais jogar), contra as autoridades governamentais portuguesas (uma compreensão que se tornou mais comum no período pós-independência), contra o partido único socialista do país independente (que não teria compreendido a importância da prática) e mais recentemente contra os que querem "trair a memória da nação" e vender os espaços tradicionais de golfe (Melo, 2011b).

A construção de narrativas heróicas se articula com a mobilização identitária do esporte: a difusão e a manutenção do hábito em vários estratos da população teriam ocorrido porque o cabo-verdiano, educado o suficiente para entender a importância do jogo, lutara para garantir o que lhe parecia um direito, um valor que construíra no próprio processo de forja do seu jeito peculiar de ser.

No caso do críquete, ainda que o processo em linhas gerais tenha sido semelhante, há diferenças que merecem ser destacadas. A primeira é que, com a criação das pioneiras agremiações de naturais (o Clube Africano de Cricket, em 1915, o Grêmio Sportivo Caboverdiano, em 1916, e o Club Sportivo Mindelense, em 1922), rapidamente aumentaram as rivalidades com os estrangeiros. A segunda é que, ao contrário do golfe, que é praticado até os dias de hoje, a partir da década de 1940 o críquete entrou em decadência. Ainda assim, continuou sendo lembrado como marca da elevação cultural dos crioulos.

Os selos dedicados ao golfe e ao críquete expressam representações bastante caras aos cabo-verdianos. As imagens de cavalheiros vestindo trajes apropriados à prática das modalidades (ainda que bastante rigorosos para uma localidade que constantemente tem altas temperaturas), inseridos na paisagem agreste do arquipélago (que a princípio se constituiria em um impedimento, não o sendo em função de uma suposta tenacidade do crioulo), vão ao encontro do imaginário construído pelos naturais. 
Um registro especial deve ser feito sobre o selo de críquete: trata-se da primeira estampilha mundial dedicada à modalidade. Para além de ser uma curiosidade, o fato de que isso tenha ocorrido em um território de colonização não inglesa nos permite pensar em comparações futuras, prospectando no contraste as opções estéticas adotadas pelo governo português, inclusive os limites dessas representações para os que conhecem a prática.

Por exemplo, no selo cabo-verdiano, vemos em posição um batsman, o jogador responsável pela defesa do wicket e rebatida da bola. John Wisden ${ }^{15}$ observa, com rigor técnico, que a posição do atleta é pouco usual e mesmo difícil de observar em uma situação cotidiana de jogo, algo que não é perceptível para quem não conhece bem a modalidade.

Não sabemos se esse detalhe foi observado, na época, pelas lideranças esportivas do arquipélago. De qualquer forma, seria necessário mais do que selos para atender aos anseios locais. Na província vinha-se denunciando o descaso metropolitano em vários âmbitos, inclusive no esportivo. Evandro de Matos, por exemplo, criticava a monocultura do futebol, fruto da falta de investimento governamental em práticas que eram consideradas de importância pelos intelectuais cabo-verdianos: "O cricket, o golfe, o tênis, estes desportos que tanto atraem pelos virtuosismos de seus lances, que tantos praticantes possuem em nossa terra - não têm sido considerados” (1951: 6).

Enfim, se os selos da série "Modalidades Desportivas" dedicados a Cabo Verde não davam conta de todas as dimensões que cercavam o esporte na província, inclusive passando ao largo tanto de tensões quanto de temas relevantes (como é o caso do futebol, já muito popular no arquipélago), ao menos parcialmente eles dialogaram com o local, atendendo, também parcialmente, aos princípios de celebrar a fraternidade imperial para a qual Portugal supostamente contribuía com seu colonialismo específico, um discurso que, ademais, tinha grande repercussão naquela colônia, que não possuía em seu território conflitos armados nem movimentos separatistas bem estruturados até a véspera da independência, em 1975.

\section{Conclusão}

A maior parte dos estudiosos do esporte no continente africano ressalta a sua ambiguidade no âmbito das relações coloniais: em algumas situações a prática foi utilizada como ferramenta de diferenciação social, em outras funcionou como uma estratégia de negociação ou de contestação dos poderes metropolitanos, em função de sua capacidade de aglutinação (Melo, 2011b). 


\section{Pequenas-grandes representações do Império Português}

Da mesma forma, a compreensão de que a emissão de selos estava a serviço dos intuitos da metrópole, ainda mais no momento do colonialismo português por nós abordado neste estudo, deve ser matizada:

O caráter ideológico presente na produção das estampas postais teria suas limitações, uma vez que não seria possível a falsificação pura e simples do passado. Para que a emissão postal tivesse algum impacto no imaginário social português era imprescindível que o material histórico fosse utilizado pelo Estado Novo de maneira coerente. Portanto, é possível que as ideias expressas nas imagens postais contassem com certa legitimidade afetiva e cultural atribuída a elas por seus destinatários (Balsinhas, 2011: 4).

De toda maneira, é fato que, nos anos 1960, selos e esportes foram utilizados pelo governo português como instrumentos a serviço da consolidação da ideia de nação, que, como vimos, se confundia com a noção de império. Ambos, aliás, têm alguns pontos em comum: são comumente utilizados pelo Estado no âmbito de suas estratégias discursivas; possuem grande poder de penetração e circulação; não se assemelham aos mecanismos políticos mais tradicionais.

Essas dimensões ajudam a entender a série "Modalidades Desportivas" como uma das ações de propaganda do Estado Novo. Esses selos nos permitem perceber que o regime, por mais autoritário que tenha sido, até por estar sofrendo pressões internacionais teve que ao menos considerar certas peculiaridades locais, nem que para tanto promovesse um deslocamento de sentidos, como o que imputava à metrópole a grande contribuição para o desenvolvimento esportivo nas províncias, um suposto sinal de sua importância no processo de "civilização" dos territórios na África e na Ásia, algo pouco provável dado inclusive o fato de que internamente, durante muito tempo, persistiram resistências à prática.

Vale destacar que, dez anos depois, o governo português uma vez mais emitiu selos com o tema para suas províncias. Em 1972, já nos momentos finais do Império, foi lançada a série "XX Jogos Olímpicos". A portaria que determinou a criação era muito similar à de 1962, só que dessa vez as modalidades foram definidas: Angola - vela; Cabo Verde - basquete e boxe; Guiné Portuguesa - levantamento de peso e lançamento de martelo; Macau - hóquei em campo; Moçambique - salto de barreira e natação; São Tomé e Príncipe - corrida e lançamento de dardo; Timor - futebol. Dessa vez foram 30 milhões de selos, nas dimensões $40 \mathrm{~mm} \times 25 \mathrm{~mm}$ (Portugal, 1972). 
Trata-se de mais um indicador de que o esporte foi mobilizado pelo governo metropolitano em sua política colonial, de alguma forma dramatizando as tensões do Império que entrava em ebulição e logo deixaria de existir como tal. É digno de nota que a série "Modalidades Desportivas" tenha registrado esse uso estratégico.

Notas

1. É importante observar que a Organização das Nações Unidas (ONU) só aceitou Portugal como membro em 1955, não só devido à sua política colonial, como também em função de seu governo de cariz autoritário.

2. Não vamos neste momento aprofundar a discussão, mas vale citar outras iniciativas que o governo português adotou para tentar manter suas colônias: abrir o território provincial para a atuação de companhias estrangeiras, oferecer espaço para bases da Organização do Tratado do Atlântico Norte (Otan), buscar um novo alinhamento com o Brasil. Para mais informações, ver Freixo (2009).

3. A ONU condenou oficialmente o colonialismo português por diversas vezes no decorrer de 1961 (Pimenta, 2010).

4. Essa linha reformista acabou derrotada no cenário político interno português, tanto no caso de Adriano Moreira, que deixou o ministério em 1963, quanto, alguns anos depois, em 1968, no que se refere às intenções de Marcelo Caetano, que substituiu Salazar, quando da enfermidade deste, na presidência do Conselho de Ministros. Só mesmo a revolução de 25 de abril de 1974 daria fim à experiência imperial portuguesa. Para mais informações, ver Pimenta (2010).

5. Por todo o mundo há muitos selos que têm como tema o esporte. Mais informações podem ser obtidas na página da
Sports Philatelists International: http://www. sportstamps.org/index.html. Acesso em: 1 out. 2011. Essa sociedade lança quatro números anuais do Fournal of Sports Philately, atualmente já no volume 50 .

6. Nesse momento, muitos outros atletas oriundos das colônias integravam equipes e selecionados das mais diferentes modalidades (Melo e Bittencourt, 2013).

7. Angola - 6 milhões; Cabo Verde - 1,5 milhão; Estado da Índia - três milhões; Guiné Portuguesa - 1,5 milhão; Macau 1,5 milhão; Moçambique -5 milhões; São Tomé e Príncipe - 1,25 milhão; Timor 1,25 milhão.

8. Os selos podem ser consultados no " $\mathrm{Ca}$ tálogo Especializado de Selos das Colônias Portuguesas/Afinsa", disponível para download em vários sítios na internet (por exemplo, em http://quiosquecpu.blogspot. com.br/2011/03/catalogos-afinsa-stampscatalogue-2011.html.

9. Os selos dessa província não chegaram a circular em função dos conflitos com a União Indiana, que em 1961 ocupou Goa, Damão e Diu.

10. Por província, estão representados os seguintes esportes: Angola - atletismo (lançamento do martelo e salto em altura), aviação, levantamento de peso, remo, polo aquático; Cabo Verde - atletismo (lançamento do dardo, corrida com barreiras e arremesso do disco), boxe, críquete, golfe; 


\section{Pequenas-grandes representações do Império Português}

Estado da Índia - atletismo (salto com vara), ciclismo, esgrima, ginástica, natação, polo (a cavalo); Guiné Portuguesa - atletismo (arremesso de peso), automobilismo, luta (não especificada, com aspecto de uma prática local), tênis, tiro (lembrando caça de aves), vôlei; Macau - atletismo (corrida de revezamento), badminton, hóquei na grama, luta (não especificada; ao contrário do caso da Guiné Portuguesa, não lembra uma prática local; o golpe se assemelha ao de uma luta esportiva, embora as vestimentas não), motociclismo, tênis de mesa; Moçambique - basquete, esqui aquático, ginástica artística (trave), hóquei sobre patins, luta livre ou greco-romana, motonáutica; São Tomé e Príncipe - pesca, mergulho, ginástica artística (argolas), vela, handebol, atletismo (corrida); Timor - caça (dois selos), futebol, ginástica, natação, hipismo.

11. Para uma discussão sobre o grau de liberdade que tinham os artistas para in-

\section{Referências bibliográficas}

ARMSTRONG, G. The migration of the Black Panther: an interview with Eusebio of Mozambique and Portugal. In: ARMSTRONG, Gary \& GIULIANOTTI, Richard (eds). Football in Africa: conflict, conciliation and community. New York: Palgrave Macmillan, 2004, p. 247-268.

BALSINHAS, Rafaela Alves da Silva. Postando o ideal: o Estado Novo português e a emissão de estampilhas moçambicanas (1933-1950). In: PPGHIS/UFRJ. IV fornada de Estudos Históricos do PPGHIS/ UFRF. Rio de Janeiro: PPGHIS/UFRJ, 2009. Disponível em:http://www.ifcs.ufrj. $\mathrm{br} /$ arshistorica/jornadas/IV jornada/IV 52.pdf. Acesso em: 1 out. $201 \overline{1}$. terferir na criação dos selos, ver Balsinhas (2011).

12. Para mais informações sobre o esporte nas províncias africanas, ver Melo, Bittencourt e Nascimento (2010) e Melo (2011a).

13. Vale a pena registrar que importantes intelectuais da colônia tiveram grande envolvimento com a prática esportiva, como é o caso de Baltasar Lopes, Amílcar Cabral e Gabriel Mariano.

14. Deve-se destacar que foi a única vez na série que três selos de uma mesma província foram dedicados a uma modalidade, o que pode denotar uma intenção de insistir em determinada representação.

15. Disponível em: http://www.espncrici nfo.com/ci/content/story/152270.html. Acesso: 29 out. 2011.

\begin{abstract}
- Postando o ideal: a emissão de selos postais moçambicanos pelo Estado Novo português (1931-1961). Dissertação (Mestrado em História Social) - Instituto de História, Universidade Federal do Rio de Janeiro. Rio de Janeiro, 2011.
\end{abstract}

BARROS, Antero. Subsídios para a história do golfem Cabo Verde. São Vicente: Clube de Golfe de São Vicente, 1981.

Cabo Verde. Praia: COC/CPV, 1998.
BARROS, Victor. Cabo Verde na memória do
império: a filatelia na simbologia das come-
morações. Comunicação apresentada na I
Jornada de História e Filatelia/Centro de


Estudos Interdisciplinares do Século XX da Universidade de Coimbra. Mimeo. Coimbra, 2010.

BOLETIM Geral do Ultramar, ano XXXVII, n. 429-430, mar.-abr. 1961.

BOLETIM Geral do Ultramar, ano XXXVIII, n. 439-440, jan./fev. 1962.

CASTELO, Cláudia. "O modo português de estar no mundo": o luso-tropicalismo e a ideologia colonial portuguesa. Porto: Afrontamento, 1998.

COELHO, João Nuno \& PINHEIROS, Francisco. A paixão do povo: história do futebol em Portugal. Porto: Afrontamento, 2002.

FERNANDES, Gabriel. Em busca da nação: notas para uma reinterpretação do Cabo Verde crioulo. Florianópolis/Praia: Editora da UFSC/Instituto da Biblioteca Nacional e do Livro, 2006.

FERRO, Marc. História das colonizações: das conquistas às independências, séculos XIII a XX. São Paulo: Companhia das Letras, 1996.

FREIXO, Adriano de. Minha pátria é a língua portuguesa. Rio de Janeiro: Apicuri, 2009.

HOBSBAWM, Eric J. Globalização, democracia e terrorismo. São Paulo: Companhia das Letras, 2007.

KNAUSS, Paulo. O desafio de fazer História com imagens: arte e cultura visual. ArtCultura, Uberlândia, v. 8, n. 12, 2006, p. 97-115.

MATOS, Evandro de. Sport. Notícias de Cabo Verde, ano 21, n. 276, out. 1951, p. 6.

MELO, Victor Andrade de. Esporte e artes plásticas em Portugal: Amadeo de SouzaCardoso. Revista Portuguesa de Ciências do Desporto, Porto, v. 10, n. 1,2010, p. 191-199.

. (Des)mobilização para a luta: o esporte como estratégia nos conflitos da Gui- né Portuguesa (décadas de 50 e 60 do século XX). Métis: História e Cultura, v. 10, n. 19, jan.-jun., 2011a, p. 215-236.

Fogos de identidade: o esporte em Cabo Verde. Rio de Janeiro: Apicuri, 2011b.

\& BITTENCOURT, Marcelo. Sob suspeita: o controle dos clubes esportivos no contexto colonial português. Tempo, Niterói, 2012. no prelo.

$\&-$ O $\mathrm{O}$ esporte na política colonial portuguesa: o Boletim Geral do Ultramar. Tempo, Niterói, 2013. no prelo.

$\&$, NASCIMENTO, Augusto (orgs.). Mais do que um jogo: o esporte no continente africano. Rio de Janeiro: Apicuri, 2010.

OSMOND, Gary. "Modest monuments"? Postage stamps and hierarchies of social memory. The fournal of Pacific History, v. 43, n. 3, 2008, p. 313-329.

\& PHILLIPS, Murray G. Enveloping the past: sport stamps, visuality and museums. The International fournal of the History of Sport, v. 26, n. 8/9, 2011, p. 1138-1155.

PEREIRA, Teresa Matos. Desenhos de África, desígnios coloniais, desejos suspensos: artes plásticas e colonialidade. Lisboa: CIEA7, 2010. Disponível em: http://repositorio-iul. iscte.pt Acesso em: 1 out. 2011.

PIMENTA, Fernando Tavares. Portugal e o século $X X$ : Estado-Império e descolonização (1890-1975). Lisboa: Edições Afrontamento, 2010.

PORTUGAL. Ministério do Ultramar. Direcção-Geral de Obras Públicas e Comunicações. Serviço de Valores Postais. Portaria n. 18899, D.R. n. 293, de 20 de dezembro de 1961.

PORTUGAL. Ministério do Ultramar. Direcção-Geral de Obras Públicas e Comunicações. Serviço de Valores Postais. Por- 
taria n. 19071. D.R. n. 55, Série I, de 12 de março de 1962a.

PORTUGAL. Ministério das Comunicações. Administração-Geral dos Correios, Telégrafos e Telefones. Direcção dos Serviços Industriais. Portaria n. 19001. D.R. n. 23, Série I, de 22 de fevereiro de 1962b.

PORTUGAL. Ministério das Comunicações. Administração-Geral dos Correios, Telégrafos e Telefones. Direcção dos Serviços Industriais. Portaria n. 19647, de 19 de janeiro de 1963.

PORTUGAL. Ministério do Ultramar. Direcção-Geral de Obras Públicas e Comunicações. Serviço de Valores Postais. Portaria n. 307/72, de 27 de maio de 1972.

SANTOS, Ana. Narrativas da nação proporcionadas pelas vitórias desportivas e seus heróis. In: APS. Sociedade portuguesa: passados recentes, futuros próximos: actas do $4^{\circ}$ Congresso Português de Sociologia.
Coimbra: APS, 2000. Disponível em: http://www.aps.pt/cms/docs_prv/docs/DP R462e05fld6d9b_1.PDF Acesso em: 1 out. 2011.

SALCEDO, Diego Andrés \& GOMES, Isaltina Maria A. M. A visibilidade da ciência nos selos postais comemorativos. Revista da Associação Nacional dos Programas de Pós-Graduação em Comunicação, Brasília, v. 12, n. 1, 2009. Disponível em: http://www.compos.org.br/seer/index.php/ e-compos/article/viewFile/263/313 Acesso em: 1 out. 2011.

SALCEDO, Diego Andrés \& SANTANA, Adriana Maria Andrade de. Memória e representação o jornalismo brasileiro: o caso do selo postal. Brazilian fournalism Research, v. 6, n. 2, 2010, p. 41-58.

SERRADO, Ricardo. O jogo de Salazar: a política e o futebol no Estado Novo. Alfragide: Casa das Letras, 2009.

\section{Resumo}

Em 1962, o governo português lançou a série postal "Modalidades Desportivas": 48 selos, seis para cada província (Angola, Cabo Verde, Estado da Îndia, Guiné Portuguesa, Macau, Moçambique, São Tomé e Príncipe, Timor), com distintos esportes representados. Este estudo objetiva analisar a emissão desse conjunto de estampilhas, com o intuito de discutir a presença da prática esportiva no âmbito da política colonial portuguesa da década de 1960. Trabalhamos a hipótese de que, por meio dos selos, o esporte foi mobilizado como estratégia para conformar uma representação de império harmônico e multirracial que respondia a pressões que pendiam sobre $o$ colonialismo português.

Palavras-chave: esporte; Portugal; colonialismo; selos.

\section{Abstract \\ In 1962, Portuguese government launched the stamp series "Sporting Modalities": 48 stamps, six for each colony (Angola, Cape Verde, State of}


India, Portuguese Guinea, Macao, Mozambique, Sao Tome and Principe, Timor), with different sports represented. This study aims to analyze the launch of these stamps, in order to discuss the presence of sports under Portuguese colonial policy in the 1960s. We worked on the hypothesis that, through the stamps, sport was mobilized as a strategy to conform a representation of empire, harmonious and multiracial, which responded to pressures that hung over Portuguese colonialism.

Key words: sports; Portugal; colonialism; stamps.

\section{Résumé}

En 1962, le gouvernement portugais a lancé la série postale "Modalités Sportives": 48 timbres, six pour chaque colonie (Angola, Cap-Vert, Etat de l'Inde, Guinée Portugaise, Macao, Mozambique, Sao Tomé et Principe, Timor), avec des différents sports représentés. Cette étude analyse l'émission de cette série de timbres, à fin de discuter la présence du sport dans la politique coloniale portugaise des années 1960. Nous avons travaillé sur l'hypothèse selon laquelle, à travers les timbres, le sport a été mobilisé comme une stratégie pour conformer une représentation de l'empire, harmonieux et multiracial, destinée à repondre aux pressions qui pesaient sur le colonialisme portugais.

Mots-clés: sport; Portugal; colonialisme; timbres. 